\title{
Prenatal Diagnosis and Treatment of Congenital Adrenal Hyperplasia
}

\author{
Saroj Nimkarn Maria I. New \\ Department of Pediatrics, Mount Sinai School of Medicine, New York, N.Y., USA
}

\section{Key Words}

21-hydroxylase deficiency · Congenital adrenal hyperplasia $\cdot$ Prenatal diagnosis $\cdot$ Prenatal treatment • Steroid hydroxylases

\begin{abstract}
Congenital adrenal hyperplasia is a group of inherited disorders caused by an enzyme deficiency in steroid biosynthesis. The most common form of congenital adrenal hyperplasia is 21-hydroxylase deficiency, which in its severe form can cause genital ambiguity in females. Steroid 21-hydroxylase deficiency can be diagnosed in utero through molecular genetic analysis of fetal DNA. Prenatal treatment successfully reduces genital ambiguity, and the subsequent problems of sex misassignment and gender confusion. Data from current studies show that prenatal diagnosis and treatment are safe for the mother and the fetus. The evidence also suggests that it is safe over the long term, but all subjects exposed to dexamethasone treatment during embryonic and fetal life should have their physical, cognitive and emotional developments recorded.

Copyright $\odot 2007$ S. Karger AG, Basel
\end{abstract}

This research is supported in part under NICHD award R37 HD00072.

\section{KARGER}

Fax +41613061234

E-Mail karger@karger.ch

www.karger.com
() 2007 S. Karger AG, Basel

Accessible online at:

www.karger.com/hre

\section{Introduction}

Congenital adrenal hyperplasia (CAH) is a group of disorders in steroid biosynthesis, caused by an enzyme deficiency in the conversion of cholesterol to cortisol. $\mathrm{CAH}$ is a monogenic, autosomal recessive disorder [1]. More than $90 \%$ of CAH cases arise from 21-hydroxylase deficiency (21OHD) [2]. Steroid 21OHD CAH occurs in two forms: a severe, or 'classical' form, and a mild, or 'nonclassical' form. Classical 21OHD CAH is further identified into salt-wasting and simple-virilizing forms. Data from close to 6.5 million newborn screenings worldwide indicate that the incidence of classical CAH ranges between 1:13,000 and 1:15,000 live births [3].

Females with the classical form of $21 \mathrm{OHD}$ are born with ambiguous genitalia owing to the overproduction of androgens from the fetal adrenal. The precursors to the 21-hydroxylase enzyme defect are shunted into the androgen pathway. The androgens then cause the virilization of external genitalia. Males do not have sexual ambiguity because the major source of androgens in males is the testes. Unlike the adrenal, the testis does not have a 21-hydroxylation pathway. The nonclassical form of $21 \mathrm{OHD}$ does not result in ambiguous genitalia in the $46, \mathrm{XX}$ female, as the prenatal level of androgens is not high enough to virilize the external genitalia of the female.

ACTH stimulation can differentiate forms of CAH. A logarithmic nomogram was developed to provide hor-

Maria I. New, M.D.

Mount Sinai School of Medicine

One Gustave L. Levy Place

Box 1198, New York, NY 10029 (USA)

Tel. +1 212241 7847, Fax +1 212241 5405, E-Mail maria.new@mssm.edu 
monal standards for diagnosis and further assignment of the $21 \mathrm{OHD}$ type by relating baseline to ACTH-stimulated serum concentrations of 17-OHP $[4,5]$.

\section{Prenatal Development}

The adrenal cortex is formed in the 4 th week of gestation from coelomic epithelial mesoderm. By the 6th or 7 th week of gestation, the provisional zones, the functional adrenal cortex of the fetus [6], secrete steroids. In affected females, elevated levels of circulating adrenal androgens interfere with vaginal and urethral canal separation, leading to a common urogenital sinus. Female genital anatomy is also affected as the androgens interact with the receptors on genital skin. This interaction induces clitoral enlargement, promotes fusion of the labial folds, and causes rostral migration of the urethral/vaginal perineal orifice. Therefore, affected females are born with virilized external genitalia including clitoromegaly and labial fusion [7]. However, internal female genitalia (uterus, fallopian tubes and ovaries) are normal as females cannot produce müllerian-inhibiting hormone since they do not have testicular Sertoli cells. Therefore the müllerian ducts do not regress, and the internal female internal genitalia develop normally.

\section{Molecular Genetics}

The gene encoding 21-hydroxylase enzyme (MIM number 201910) is mapped to the short arm of chromosome 6 (6p21.3). There is a corresponding inactive pseudogene, CYP21A1P, which is $98 \%$ homologous to the active gene CYP21A2 [8]. Unequal crossing over during meiosis can result in deletion of the gene. Gene conversion transfers deleterious point mutations from the pseudogene gene to the active gene, causing either complete or partial deficiency of 21-hydroxylase activity [9]. More than 100 mutations have been described, including point mutations, small deletions, small insertions and complex rearrangements of the gene [10]. About $20 \%$ of the mutant alleles are meiotic recombinations deleting a $30-\mathrm{kb}$ gene segment [11] that encompasses the $3^{\prime}$ end of the CYP21A1P pseudogene, all of the adjacent C4B complement gene, and the $5^{\prime}$ end of CYP21A2, producing a nonfunctional chimeric pseudogene. Another common mutation is the Intron 2 splice mutation ( $656 \mathrm{~A} / \mathrm{C}$ to $\mathrm{G})$, occurring with a frequency of $20-30 \%$.

\section{Genotype-Phenotype Correlation}

In $21 \mathrm{OHD} \mathrm{CAH}$, genotypes can be used to predict the disease severity. In autosomal recessive disorders, the expressed phenotype reflects the less severe mutation of the patients' alleles. The severity of each mutation is characterized by the percentage of the remaining enzyme activity found by in vitro expression studies. In table 1, the common mutations and the phenotypes are described. Salt-wasters usually have the most severe mutations (homozygous deletions), while nonclassical patients usually have the milder V281L mutation [12]. However, a considerable degree of divergence is observed within mutation groups with intermediate severity [13]. Genotype-phenotype nonconcordance occurs, although infrequently, with less severe allelic mutations such as V281L, P30L, and I172N. In addition, the splice mutation in Intron 2 is commonly associated with phenotypic variation of saltwasting severity, which can be explained by variable splicing. In the context of prenatal diagnosis, it is important to distinguish classical and nonclassical genotypes in order to determine the necessity of prenatal treatment. In our series of publications on prenatal diagnosis $[1,14]$, we divided the genotypes into mutation identical groups. V281L is known to cause a nonclassical phenotype, and therefore should not indicate prenatal dexamethasone treatment. However, in approximately $5 \%$ of our prenatal diagnoses, the homozygous V281L in combination with a severe allelic mutation (compound heterozygote) resulted in a newborn with the classical disease. We have also found the P30L mutation to cause nonconcordance, but less frequently than the V281L mutation $[13,15,16]$. In our recent review of 723 patients from mixed ethnic backgrounds (unpublished data), the classical versus nonclassical phenotype could be predicted from genotypes in most cases. However, rare exceptions existed when patients carried the V281L and P30L mutations. These mutations conferred the classical phenotype in less than $3 \%$ of the patients when a nonclassical phenotype was expected. Stikkelbroeck et al. [17] demonstrated that a very small percentage of patients who carried I172N and another severe mutation presented with a nonclassical phenotype when a classical phenotype was expected.

In families where the proband is a virilized female, predicting the risk of genital virilization in subsequent female fetuses is feasible. If the proband is a male, prediction of phenotype based on genotype is not possible and the subsequent affected female fetus must be treated until term to avoid genital ambiguity. 
Table 1. Common gene mutations of the 21-hydroxylase gene CYP21A2 [49]

\begin{tabular}{|c|c|c|c|c|c|}
\hline $\begin{array}{l}\text { Exon/ } \\
\text { Intron }\end{array}$ & Mutation type & Mutation & Phenotype & $\begin{array}{l}\text { Severity of enzyme defect } \\
\text { (\% enzyme activity) }\end{array}$ & References \\
\hline \multicolumn{6}{|c|}{ 1. Nonclassical mutations } \\
\hline Exon 1 & Missense mutation & P30L & $\mathrm{NC}$ & Mild (30-60\%) & Tusie-Luna, 1991 \\
\hline Exon 7 & Missense mutation & V281L & $\mathrm{NC}$ & Mild (20-50\%) & Speiser, 1988 \\
\hline Exon 8 & Missense mutation & $\mathrm{R} 339 \mathrm{H}$ & $\mathrm{NC}$ & Mild (20-50\%) & Helmberg, 1992 \\
\hline Exon 10 & Missense mutation & P453S & $\mathrm{NC}$ & Mild (20-50\%) & $\begin{array}{l}\text { Helmberg, 1992; } \\
\text { Owerbach, } 1992\end{array}$ \\
\hline \multicolumn{6}{|c|}{ 2. Classical mutations } \\
\hline Deletion & $30-\mathrm{kb}$ deletion & - & SW & Severe $(0 \%)$ & White, 1984 \\
\hline Intron 2 & Aberrant splicing of Intron 2 & $656 \mathrm{~A} / \mathrm{C}-\mathrm{G}$ & SW, SV & Severe (ND) & Higashi, 1988 \\
\hline Exon 3 & Eight-base deletion & G110 $\Delta 8 \mathrm{nt}$ & SW & Severe $(0 \%)$ & White, 1994 \\
\hline Exon 4 & Missense mutation & $\mathrm{I} 172 \mathrm{~N}$ & SV & Severe (1\%) & $\begin{array}{l}\text { Amor, 1988; } \\
\text { Tusie-Luna, } 1990\end{array}$ \\
\hline Exon 6 & Cluster mutations & I236N, V237E, M239K & SW & Severe $(0 \%)$ & $\begin{array}{l}\text { Amor, 1988; } \\
\text { Tusie-Luna, } 1990\end{array}$ \\
\hline Exon 8 & Nonsense mutation & Q318X & SW & Severe $(0 \%)$ & Globerman, 1988 \\
\hline Exon 8 & Missense mutation & R356W & SW, SV & Severe $(0 \%)$ & Chiou, 1990 \\
\hline Exon 10 & Missense mutation & $\mathrm{R} 483 \mathrm{P}^{*}$ & SW & Severe $(1-2 \%)$ & Wedell, 1993 \\
\hline
\end{tabular}

$\mathrm{NC}=$ Nonclassical; $\mathrm{ND}=$ not determined; $\mathrm{SV}=$ simple virilizing; $\mathrm{SW}=$ salt-wasting.

\section{Prenatal Diagnosis of 210HD}

A number of approaches to prenatal identification of affected fetuses have been used. In 1965, Jeffcoate et al. [18] first reported a successful prenatal diagnosis of $21 \mathrm{OHD}$ based on elevated levels of 17-ketosteroids and pregnanetriol in amniotic fluid. The hormonal diagnostic test for 21OHD is amniotic fluid 17-OHP. Androstenedione $\Delta^{4}$ may also be employed as an adjunctive diagnostic assay [19]. Hormonal diagnosis is only currently used when molecular diagnosis is unavailable.

Recent advances in genotyping of the CYP21A2 gene have made molecular genetic studies of extracted fetal DNA, the ideal method to diagnose 21OHD CAH in the fetus [9]. Approximately $95-98 \%$ of the mutations causing $21 \mathrm{OHD}$ have been identified through a combination of molecular genetic techniques studying large gene rearrangement, and arrays of point mutations [20-22]. Chorionic villus sampling (CVS), rather than amniocentesis, with molecular genotyping is the preferred diagnostic method in use. CVS is performed at the 8th-9th week of gestation, while amniocentesis is usually performed at the 12th-13th week of gestation. As we only wish to treat affected females till term and only $1 / 4$ of the fetuses will be affected and $1 / 2$ will be males, 7 out of 8 fetuses do not require treatment. Thus, amniocentesis, which is performed later in gestation, results in treatment of unaffected fetuses for a longer period of time than CVS. However, amniocentesis can be used as an alternative, reliable method of prenatal diagnosis when CVS is unavailable. In such instances, the supernatant is used for hormonal measurement and the cells are cultured to obtain a genotype through DNA analysis. The supernatant hormone measurements are only positive when the fetus is a saltwaster [1].

Nonetheless, pitfalls do occur in a small percentage of the patients undergoing prenatal diagnosis, such as undetectable mutations [23], allele drop out [24], or maternal DNA contamination. Determination of satellite markers may increase the accuracy of molecular genetic analysis [25].

Studying fetal DNA from maternal plasma may reduce the need for invasive procedures to obtain fetal samples in at-risk pregnancies if analysis of the fetal DNA becomes possible at the optimal time of gestation. Reports of sex determination from fetal DNA in maternal plasma show promise [26,27], but require more confirmation of the successful results. 
Fig. 1. Simplified algorithm for prenatal diagnosis and treatment of $\mathrm{CAH}$.

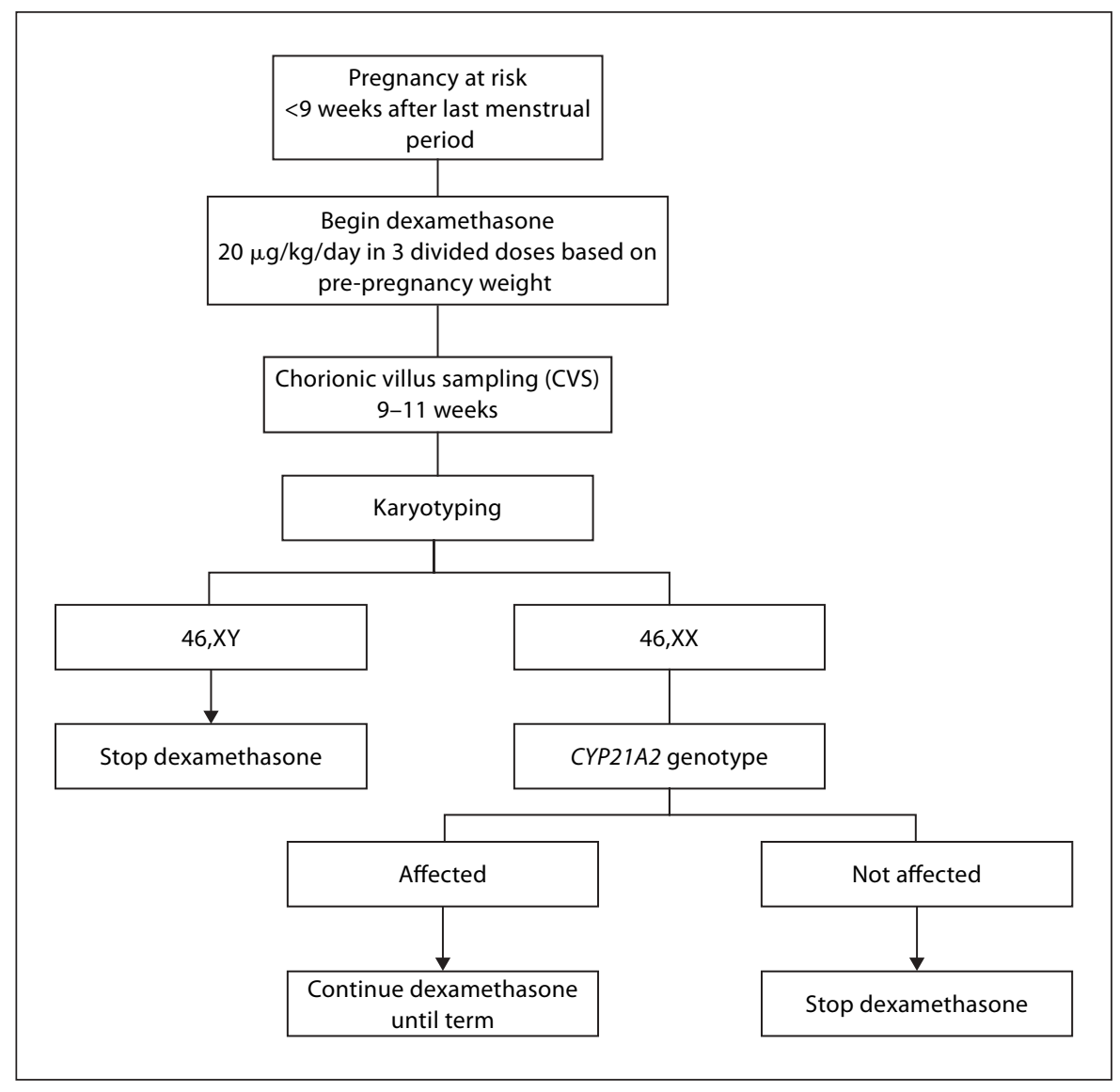

\section{Preimplantation Diagnosis}

Preimplantation genetic diagnosis identifies genetic abnormalities in preimplantation embryos prior to embryo transfer, so only unaffected embryos established from IVF are transferred. The procedure has been utilized in many monogenic recessive disorders such as cystic fibrosis, hemoglobinopathies, spinal muscular atrophy and Tay-Sachs disease. Preimplantation genetic diagnosis is being used for a growing number of genetic diseases [28]. Preimplantation diagnosis has not been utilized in $\mathrm{CAH}$ except for one report which did not result in a pregnancy [28]. It would be desirable to have further studies of preimplantation diagnosis in $\mathrm{CAH}$ families.

\section{Prenatal Treatment}

In $21 \mathrm{OHD}$, prenatal treatment with dexamethasone has been used since 1984 [29]. Institution of therapy before the 8 th week of gestation, prior to the onset of adrenal androgen secretion, effectively suppresses excessive adrenal androgen production and prevents virilization of external female genitalia. Dexamethasone is used because it binds minimally to cortisol-binding globulin in the maternal blood, and unlike hydrocortisone, escapes inactivation by placental $11 \beta$-hydroxysteroid dehydrogenase enzyme. Thus, dexamethasone crosses the placenta from the mother to the fetus and suppresses ACTH secretion with a longer half life than other synthetic steroids [14].

When dexamethasone administration begins as early as the 8th week of gestation, the treatment is blind to the disease status and sex of the fetus. If the fetus is later determined upon karyotype to be a male, or an unaffected female upon DNA analysis, treatment is discontinued. Otherwise, treatment is continued to term [19]. A simplified algorithm of management of potentially affected pregnancies is shown in figure 1 . The optimal dosage and timing is $20 \mu \mathrm{g} / \mathrm{kg} /$ day of dexamethasone per maternal pre-pregnancy body weight, in three divided doses, starting as soon as pregnancy is confirmed, and no later than 
9 weeks after the last menstrual period [30, 31]. The mother's blood pressure, weight, glycosuria, $\mathrm{HbA}_{1 \mathrm{C}}$, symptoms of edema, striae and other possible adverse effects of dexamethasone treatment should be carefully observed throughout pregnancy. Urinary estriol may be monitored in the mother after 15-20 weeks of gestation to indicate fetal adrenal suppression, and to assure compliance [32].

\section{Outcome of Prenatal Treatment}

Although some uncertainties and concerns remain about the long-term safety of prenatal diagnosis and treatment [33], compelling data from large cohorts of pregnancies with prenatal diagnosis and treatment [14, 34] prove its efficacy and safety.

\section{Effects of Prenatal Treatment}

Dexamethasone administered at or before the 9th week of gestation is effective in reducing genital virilization as demonstrated by the difference in Prader score of treated versus untreated affected females [32] (fig. 2). In families with both treated and untreated affected females, genital virilization in the treated siblings was decreased (fig. 3). Treated newborns whose genitalia were rated Prader III-IV had delayed treatment initiation, were undertreated by the referring physician, or were incorrectly dosed due to maternal noncompliance.

\section{Maternal and Fetal Tolerance of Dexamethasone \\ Treatment \\ The Mother}

In our experience, mothers receiving dexamethasone treatment did not have enduring side effects $[14,35]$. The weight gain, edema and striae disappeared upon cessation of therapy. No differences were demonstrated in terms of hypertension or gestational diabetes. Swedish researchers [36] have also found that treated and untreated pregnant mothers did not differ in blood pressure, glycosuria and proteinuria. In one report from France, 18\% of the treated mothers reported some side effects, but only $2 \%$ of them were considered to have more severe complications [34]. In our study [14], all the mothers who received prenatal treatment (partial and full-term) stated that they would take dexamethasone again for a future pregnancy. A retrospective survey [37] of 38 mothers' attitudes and experiences towards prenatal diagnosis and treatment indicated that diagnostic procedures of both amniocentesis and CVS were well-tolerated. The anxiety

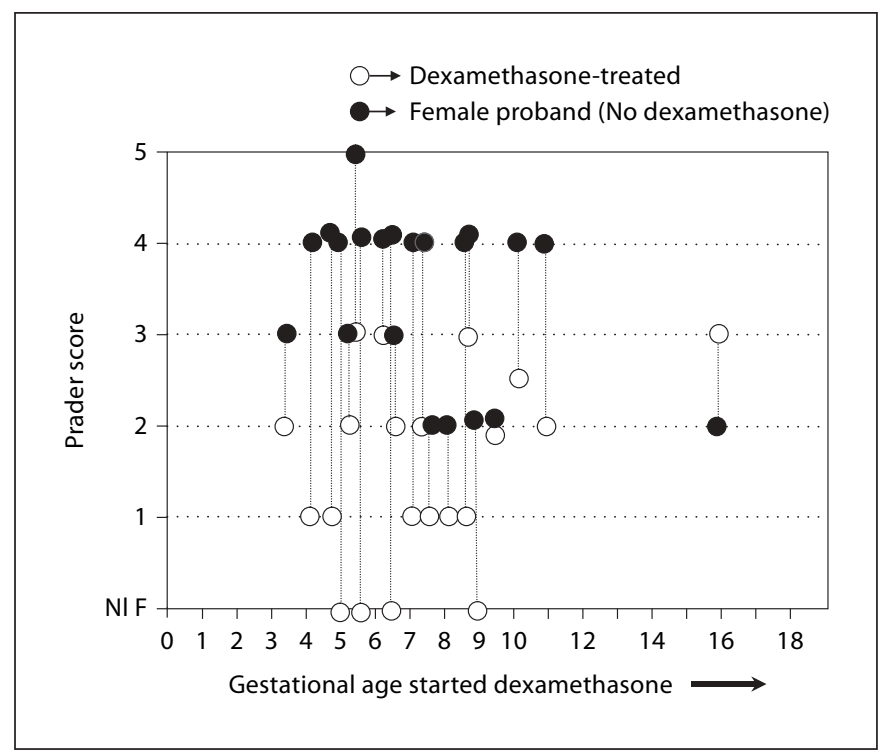

Fig. 2. Genitalia of untreated (Prader IV) versus prenatally dexamethasone-treated (Prader I) siblings with congenital adrenal hyperplasia. Treatment was from 5 weeks of gestation until term.
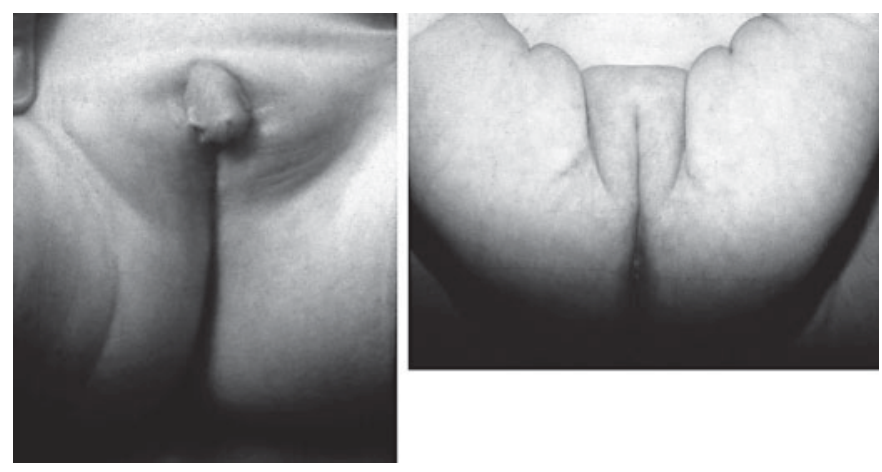

Fig. 3. Prader stages of affected female infants in monitored, prenatally treated pregnancies.

or discomforts from the procedures were outweighed by the knowledge of the disease status of the fetus. All women chose to undergo dexamethasone treatment again in future pregnancies.

\section{The Fetus}

In our comprehensive studies of almost 600 pregnancies $[14,35]$, prenatally treated newborns did not differ in weight, length or head circumference from untreated, unaffected siblings. The gestational length and rate of fe- 
tal wasting did not differ. Postnatal growth has been normal in followed cases: a long-term follow-up study in Scandinavia demonstrated that 44 children treated prenatally had normal pre- and postnatal growth compared to matched controls [36].

Rare and isolated adverse events of prenatal dexamethasone treatment have been reported in treated children, but no harmful effects that can be clearly attributed to the treatment have been documented [38]. The incidence of fetal deaths in treated pregnancies does not exceed that predicted for the general population [39]. Importantly, no cases have been reported of cleft palate, placental degeneration or fetal death, which have been observed in a rodent model of in utero exposure to highdose glucocorticoids [40].

\section{Long-Term Effects of Dexamethasone Treatment}

Long-term follow-up studies of treated fetuses are lacking, but are underway in our group [32]. Long-term follow-up studies providing extensive data on the somatic and neuropsychological outcomes of glucocorticoid treatment are being investigated.

The authors' group has engaged in studying developmental outcomes in children prenatally expose to dexamethasone. The preliminary results are summarized below:

First Study Phase. The first pilot study examined the cognitive and behavioral development of 26 prenatally treated children aged 6 months to $51 / 2$ years compared to 14 untreated children. There were no significant differences between the two groups studied, except that the treatment group had more internalizing behaviors than the untreated children, such as shyness, less sociability, greater avoidance, and a marginal increase in emotionality [41]. Another analysis of standard questionnaires regarding gender related behavior was completed in 17 prenatally treated girls among $78 \mathrm{CAH}$ affected girls, ages $2-12$. The analysis showed that gender related behavior correlated with the degree of virilization at birth determined by Prader score [42].

Second Study Phase. In the second phase of the study, more thorough questionnaires (also administered to mothers) were used. Development outcomes of 174 prenatally children were compared to 313 unexposed children, ages 1 month to 12 years of age [43]. None of the developmental areas, including cognitive, motor, language, social, and self-help skills, were different between the two groups.

Third Study Phase. In the third phase of the study, physical observation and interviews were completed for
140 children, ages $5-12$. Approximately $1 / 3$ of the participants were affected with CAH, and $1 / 2$ of the affected children were treated with dexamethasone. The study confirmed what was found in second study phase: prenatally treated children did not suffer adverse cognitive effects [44]. The study did find that dexamethasoneexposed CAH girls showed less masculine gender role behavior overall than the CAH girls unexposed to dexamethasone. When gender-related behaviors were blindly assessed during interview and observation using several combined tools, there was no difference between the treated and untreated groups in regards to gender identity [45].

Our group continues our commitment to long-term follow-up studies of developmental outcomes of prenatal treatment, focusing on cognition, gender, temperament and handedness (as indicator of prenatal androgen effects). Large-scale, international studies of cognitive function and psychological outcomes have been initiated to confirm the safety of treatment, and to enhance our understanding of prenatal steroid exposure in humans $[35,38]$.

\section{Treatment Failures}

Although we have seen great success with prenatal treatment, treatment failures occur. These failures have been attributed to the cessation of therapy in midgestation, noncompliance or suboptimal dosing, though some reports provide no ready explanation for the failure [46, 47]. Studies before 1993 must be viewed with caution, however, as it was then common practice then to discontinue dexamethasone treatment to obtain hormonal values in amniotic fluid [48]. Discontinuing dexamethasone treatment for even a short period during sexual differentiation increases the likelihood of genital virilization in affected female newborns. Protocols also varied between institutions.

\section{Conclusion}

There is accurate, extensive, and compelling data from the human studies pointing to the benefit and safety of prenatal treatment. When properly introduced, prenatal diagnosis and treatment of $21 \mathrm{OHD}$ spares the affected female of the consequences of genital ambiguity, which is a crucial and complicated morbidity in 21OHD CAH. Treatment with dexamethasone is effective in reducing genital virilization, the risk of sex misassignment, and unnecessary genitoplasty. In prenatal diagnosis of 
21OHD CAH, prompt and accurate genetic diagnosis is crucial to minimize the duration of dexamethasone exposure in the 7 out of 8 fetuses who must be treated, but are not classically affected females. Based on current studies, proper prenatal diagnosis and treatment are safe for both the fetus and the mother. Studies of treated versus untreated pregnancies will monitor the safety of treatment, and enhance our understanding of the effects of prenatal steroid exposure to the human brain. Long-term studies underway in our group will evaluate long-term safety. Prenatal treatment of $21 \mathrm{OHD} \mathrm{CAH}$ is the first instance of successful treatment of an inborn metabolic disorder. At present, there are very few genetic disorders for which prenatal treatment is effective in improving the phenotypic outcome, as well as future prognosis.

\section{Acknowledgements}

The authors would like to thank Claire Gilbert and Naomi Horowitz for their assistance in preparing the manuscript.

\section{References}

1 New M: Prenatal treatment of congenital adrenal hyperplasia: the United States experience. Endocrinol Metab Clin North Am 2001;30:1-13.

2 New MI, White PC: Genetic disorders of steroid metabolism; in Thakker RV (ed): Genetic and Molecular Biological Aspects of Endocrine Disease. London, Bailliere Tindall, 1995, pp 525-554.

- 3 Pang SY, Wallace MA, Hofman L, Thuline HC, Dorche C, Lyon IC, et al: Worldwide experience in newborn screening for classical congenital adrenal hyperplasia due to 21-hydroxylase deficiency. Pediatrics 1988;81: 866-874.

-4 New MI, Wilson RCW: Steroid disorders in children: congenital adrenal hyperplasia and apparent mineralocorticoid excess. Proc Natl Acad Sci USA 1999:12790-12797.

5 Nimkarn S, Weerakulwattana L, Panamonta O, Kumpornsin K, Limwongse C: Standardized biochemical diagnosis of 21-hydroxylase congenital adrenal hyperplasia, the forgotten essentials; in The Endocrine Society of Thailand, 15th Annual Meeting; 2003 October 30-November 1. Bangkok, Thailand, The Endocrine Society of Thailand, 2003, pp 12-13.

6 Villee DB: The development of steroidogenesis. Am J Med 1972;53:533-544.

7 New MI: An update of congenital adrenal hyperplasia. Ann N Y Acad Sci 2004;1038: $14-43$.

8 White PC, New MI, Dupont B: Structure of the human steroid 21-hydroxylase genes. Proc Natl Acad Sci USA 1986;83:5111-5115.

$\checkmark 9$ White P, Speiser P: Congenital adrenal hyperplasia due to 21-hydroxylase deficiency. Endocr Rev 2000;21:245-291.

10 Stenson PD, Ball EV, Mort M, Phillips AD, Shiel JA, Thomas NS, et al: Human Gene Mutation Database (HGMD): 2003 update. Hum Mutat 2003;21:577-581.

11 White P, Vitek A, Dupont B, New M: Characterization of frequent deletions causing steroid 21-hydroxylase deficiency. Proc Natl Acad Sci USA 1998;85:4436-4440.
12 Wilson RC, Mercado AB, Cheng KC, New MI: Steroid 21-hydroxylase deficiency: genotype may not predict phenotype. J Clin Endocrinol Metab 1995;80:2322-2329.

13 Krone N, Braun A, Roscher A, Knorr D, Schwarz H: Predicting phenotype in steroid 21-hydroxylase deficiency? Comprehensive genotyping in 155 unrelated, well defined patients from southern Germany. J Clin Endocrinol Metab 2000;85:1059-1065.

14 New M, Carlson A, Obeid J, Marshall I, Cabrera M, Goseco A, et al: Extensive personal experience: prenatal diagnosis for congenital adrenal hyperplasia in 532 pregnancies. J Clin Endocrinol Metab 2001;86:5651-5657.

15 Dolzan V, Solyom J, Fekete G, Kovacs J, Rakosnikova V, Votava F, et al: Mutational spectrum of steroid 21-hydroxylase and the genotype-phenotype association in Middle European patients with congenital adrenal hyperplasia. Eur J Endocrinol 2005;153:99106.

16 Friaes A, Rego AT, Aragues JM, Moura LF, Mirante A, Mascarenhas MR, et al:CYP21A2 mutations in Portuguese patients with congenital adrenal hyperplasia: identification of two novel mutations and characterization of four different partial gene conversions. Mol Genet Metab 2006;88:58-65.

17 Stikkelbroeck NM, Hoefsloot LH, de Wijs IJ, Otten BJ, Hermus AR, Sistermans EA: CYP21 gene mutation analysis in 198 patients with 21-hydroxylase deficiency in The Netherlands: six novel mutations and a specific cluster of four mutations. J Clin Endocrinol Metab 2003;88:3852-3859.

18 Jeffcoate T, Fleigner J, Russell S, Davis J, Wade A: Diagnosis of the adrenogenital syndrome before birth. Lancet 1965;2:553.

19 New M, Marshall I: Adrenal disorders. Pediatric endocrinology; in De Groot L (ed): Endotext (http://www.endotext.org).

20 Lee HH, Lee YJ, Chan P, Lin CY: Use of PCR based amplification analysis as a substitute for the southern blot method for CYP21 deletion detection in congenital adrenal hyperplasia. Clin Chem 2004;50:1074-1076.
21 Nimkarn S, Weerakulwattana L, Chaichanwatanakul K, et al: Comprehensive study of congenital adrenal hyperplasia due to 21-hydroxylase deficiency in 92 Thai patients; in 11th Asian Congress of Pediatrics; 2003 November 2-7. Bangkok, Thailand, 11th Asian Congress of Pediatrics, 2003, p 80.

22 Tukel T, Uyguner O, Wei J, Yuksel-Apak M, Saka N, Song D, et al: A novel semiquantitative polymerase chain reaction/enzyme digestion-based method for detection of large scale deletions/conversions of the CYP21 gene and mutation screening in Turkish families with 21-hydroxylase deficiency. J Clin Endocrinol Metab 2003;88:5893-5897.

23 Mao R, Nelson L, Kates R, Miller CE, Donaldson DL, Tang W, et al: Prenatal diagnosis of 21-hydroxylase deficiency caused by gene conversion and rearrangements: pitfalls and molecular diagnostic solutions. Prenat Diagn 2002;22:1171-1176.

24 Day DJ, Speiser PW, Schulze E, Bettendorf $\mathrm{M}$, Fitness J, Barany F, et al: Identification of non-amplifying CYP21 genes when using PCR-based diagnosis of 21-hydroxylase deficiency in congenital adrenal hyperplasia (CAH) affected pedigrees. Hum Mol Genet 1996;5:2039-2048.

-25 Section on Endocrinology and Committee on Genetics: Technical report: congenital adrenal hyperplasia. Pediatrics 2000;106: 1511-1518.

26 Rijnders RJ, van der Schoot CE, Bossers B, de Vroede MA, Christiaens GC: Fetal sex determination from maternal plasma in pregnancies at risk for congenital adrenal hyperplasia. Obstet Gynecol 2001;98:374-378.

27 Costa JM, Benachi A, Gautier E: New strategy for prenatal diagnosis of X-linked disorders. N Engl J Med 2002;346:1502.

-28 Fiorentino F, Biricik A, Nuccitelli A, De Palma R, Kahraman S, Iacobelli M, et al: Strategies and clinical outcome of 250 cycles of preimplantation genetic diagnosis for single gene disorders. Hum Reprod 2006;21:670684 
-29 David M, Forest MG: Prenatal treatment of congenital adrenal hyperplasia resulting from 21-hydroxylase deficiency. J Pediatr 1984;105:799-803.

$\checkmark 30$ Mercado AB, Wilson RC, Cheng KC, Wei JQ, New MI: Extensive personal experience: prenatal treatment and diagnosis of congenital adrenal hyperplasia owing to steroid 21-hydroxylase deficiency. J Clin Endocrinol Metab 1995;80:2014-2020.

31 Carlson AD, Obeid JS, Kanellopoulou N, Wilson RC, New MI: Congenital adrenal hyperplasia: update on prenatal diagnosis and treatment; in Labrie F (ed): Xth International Congress on Hormonal Steroids; 1999 June 17-21, 1998. Quebec, Canada, J Steroid Biochem Mol Biol, 1999, pp 19-29.

-32 Clayton PE, Miller WL, Oberfield SE, Ritzen EM, Sippell WG, Speiser PW: Consensus statement on 21-hydroxylase deficiency from the European Society for Paediatric Endocrinology and the Lawson Wilkins Pediatric Endocrine Society. Horm Res 2002;58:188195.

\$3 Seckl JR, Miller WL: How safe is long-term prenatal glucocorticoid treatment? JAMA 1997;277:1077-1079.

34 Forest M: Prenatal diagnosis, treatment, and outcome in infants with congenital adrenal hyperplasia. Curr Opin Endocrinol Diabet 1998;4:209-217.
35 New M, Carlson A, Obeid J, Marshall I, Cabrera M, Goseco A, et al: Update: Prenatal diagnosis for congenital adrenal hyperplasia in 595 pregnancies. Endocrinologist 2003; 13:233-239.

36 Lajic S, Wedell A, Bui T, Ritzen E, Holst M: Long-term somatic follow-up of prenatally treated children with congenital adrenal hyperplasia. J Clin Endocrinol Metab 1998;83: 3872-3880.

37 Trautman PD, Meyer-Bahlburg HFL, Postelnek J, New MI: Mothers' reactions to prenatal diagnostic procedures and dexamethasone treatment of CAH. J Psychosom Obstet Gynaecol 1996;17:175-181.

38 Lajic S, Nordenstrom A, Ritzen EM, Wedell A: Prenatal treatment of congenital adrenal hyperplasia. Eur J Endocrinol 2004;151(suppl 3):U63-U69.

39 Koops BL, Morgan LJ, Battaglia FC: Neonatal mortality risk in relation to birth weight and gestational age: update. J Pediatr 1982; 101:969-977.

40 Goldman A, Sharpior B, Katsumata M: Human foetal palatal corticoid receptors and teratogens for cleft palate. Nature 1978;272: 464-466.

41 Trautman PD, Meyer-Bahlburg HF, Postelnek J, New MI: Effects of early prenatal dexamethasone on the cognitive and behaviora development of young children: results of a pilot study. Psychoneuroendocrinology 1995;20:439-449.

42 Meyer-Bahlburg H, Baker S, Carlson A, Obeid J, Vogiatzi M, Dolezal C, et al: Does genital status at birth predict gender-related behavior in girls with congenital adrenal hyperplasia; in International Academy of Sex Research 27th Annual Meeting. Montreal, Quebec, Canada, 2001, p 41.
43 Meyer-Bahlburg H, Dolezal C, Baker S, Carlson A, Obeid J, New M: Cognitive and motor development of children with and without congenital adrenal hyperplasia after earlyprenatal dexamethasone. J Clin Endocrinol Metab 2004;89:610-614.

$\checkmark 44$ Meyer-Bahlburg H, Dolezal C, Haggerty R, Baker S, Enfield L, Sihler B, et al: Performance on cognitive tests in children with a history of prenatal dexamethasone exposure. Pediatr Res 2001;49:3-341.

45 Meyer-Bahlburg H, Dolezal C, Baker S, Carlson A, Obeid J, Vogiatzi M, et al: Diminished behavioral masculinization in girls with congenital adrenal hyperplasia after prenatal dexamethasone exposure. Horm Behav 2003;44:64.

46 Speiser P, White P: Congenital adrenal hyperplasia. N Engl J Med 2003;349:776-788.

47 Pang S, Clark A: Newborn screening, prenatal diagnosis, and prenatal treatment of congenital adrenal hyperplasia due to 21-hydroxylase deficiency. Trends Endocrinol Metab 1990;1:300-307.

48 New M: Prenatal treatment of congenital adrenal hyperplasia: authors differ with technical report. Pediatrics 2001;107:804.

49 Stenson PD, Ball EV, Mort M, Phillips AD, Shiel JA, Thomas NS, et al: Human Gene Mutation Database (MGMD): 2003 update. Hum Mutat 2003;21:577-581. 